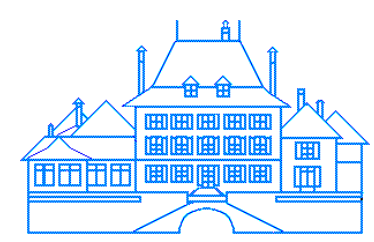

STUDIENZENTRUM GERZENSEE

STIFTUNG DER SCHWEIZERISCHEN NATIONALBANK

\title{
THE MECHANICS OF A SUCCESSFUL \\ EXCHANGE-RATE PEG: LESSONS \\ FOR EMERGING MARKETS
}

Michael Dueker and Andreas M. Fischer

Working Paper No. 01.02

This discussion paper series represents research work-in-progress and is distributed with the intention to foster discussion. The views herein solely represent those of the authors. No research paper in this series implies agreement by the Study Center Gerzensee and the Swiss National Bank, nor does it imply the policy views, nor potential policy of those institutions. 
Michael Dueker is research officer at the Federal Reserve Bank of St. Louis. Andreas M. Fischer is economic adviser at the Swiss National Bank, Zurich, Switzerland. Mrinalini Lhila provided research assistance.

\title{
The Mechanics of a Successful Exchange-Rate Peg: Lessons for Emerging Markets
}

\author{
Michael Dueker and Andreas M. Fischer
}

April 18, 2001

\begin{abstract}
To the surprise of many market watchers, Thailand's exchange-rate peg to the dollar collapsed in July 1997, leading to similar rounds of currency devaluations in other East Asian countries. This study seeks to determine if there were identifiable contrasts in implementation between Thailand's peg and a perennially successful peg-Austria's peg to the Deutsche mark - that would have hinted at problems for Thailand prior to July 1997. The comparison suggests that Thailand was not sufficiently vigilant about keeping its inflation rate low in the early 1990s. By 1995, Thailand faced a situation where a tight monetary policy involving high domestic interest rates would not always have created disinflationary pressure, as high interest rates also tended to attract greater capital inflow to Thailand. In this environment, Thailand's monetary policy became erratic and failed to maintain the exchange-rate peg.
\end{abstract}




\section{Non Technical Summary}

\section{The Mechanics of a Successful Exchange-Rate Peg: Lessons for Emerging Markets}

Exchange-rate pegs collapsed in many countries in the 1990s, leading to dreary assessments of the merits of pegged exchange rates. Whether one points to the failure of Mexico's peg in December 1994 or to the sharp devaluations in East Asia in 1997-98, in Russia in August 1998, and in Brazil in January 1999, the collapse of unilateral exchange rate pegs often preceded acute financial macroeconomic crises. Despite recent failures, however, exchange rate pegs remain a prevalent policy choice. Calvo and Reinhart (2000) argue that high exchange-rate volatility, which accompanies a floating exchange rate regime, is particularly onerous to emerging markets. A float may still be preferred to a peg that reduces the variability of the exchange rate, even if it does not attain the complete confidence of investors. Given the continued prevalence of pegs, it is worth seeking additional understanding of what makes a peg successful or not.

For this reason, we find it useful to study what was arguably the most successful unilateral exchange rate peg, Austria's peg to the Deutsche mark prior to Austria's entry into the European Monetary System in 1995. An estimated model of Austrian monetary policy mechanics helps identify salient features that made the Austrian peg credible to the public. We then apply the same model to Thailand's monetary policy, the East Asian country, among the countries that eventually devalued, that had maintained the tightest peg to the U.S. dollar prior to July 1997. The conventional wisdom is that the currency crisis in Thailand came without warning and caught financial markets by surprise. We would like to determine if there were any contrasts between the Austrian and Thai pegs that would have hinted at problems for Thailand prior to July 1997.

In our empirical model of monetary policy mechanics, we assume that a pegging central bank adjusts its interest rate according to a forecast of the relationship between the policy instrument and domestic price inflation, which is presumably close to the rate of inflation in the anchor currency. For a pegging central bank, we add two feedback terms that indicate the response to an exchange rate gap and an inflation gap. The exchange rate gap is between the actual and target exchange rate. The inflation gap is between inflation in the home country and the anchor country. The coefficients on the feedback terms, which are subject to Markov switching, indicate by how much the respective gaps alter this period's desired rate of inflation relative to the baseline target

One lesson that emerges from results for Austria is that pegging countries ought to behave like assiduous inflation targeters even when there is no pressure on the exchange rate. The key is that the inflation target should be the same inflation target used in the anchor country, because the nominal exchange rate can no 
longer move to correct an overvalued real exchange rate. A second lesson is to take care in choosing an anchor currency, because the major currencies experience wide swings against one another. It makes little sense to tie one's currency to the dollar if the fluctuations in the exchange value of the dollar against other major currencies are difficult to withstand.

Both of these lessons appear to apply to Thailand's peg to the U.S. dollar. The Bank of Thailand allowed the domestic inflation rate to exceed the U.S. inflation rate prior to the middle of 1995. If the Bank of Thailand had a true long-term commitment to pegging to the dollar, it should not have tried to take advantage of the depreciation in the dollar against the yen by inflating. This policy led to trouble when the U.S. dollar began to appreciate against the yen in the second half of 1995. At that point it would have been exceedingly difficult for inflation in Thailand to undershoot the U.S. inflation rate by a significant margin. The Bank of Thailand might have been better off by announcing gradual depreciation of the nominal exchange rate, starting in mid-1995, before speculators began to apply pressure.

Since the crisis in 1997-1998, the Bank of Thailand announced a new inflation targeting regime in place of an exchange rate peg. The Bank of Thailand believes that the new regime will be less prone to boom and bust cycles than was the peg. Thus, Thailand is one emerging market that has decided that it can find greater stability by promising low inflation than by promising a particular exchange rate. Time will tell whether the disadvantages of floating exchange rates to emerging markets will weigh as heavily as Calvo and Reinhart suggest. What is clear from the results presented here is that Thailand's exchange rate peg prior to July 1997 never had the same strong underpinnings that Austria's peg to the Deutsche mark had. 
Exchange rate pegs collapsed in many countries in the 1990s, leading to dreary assessments of the merits of pegged exchange-rate regimes. Whether one points to the failure of Mexico's peg in December 1994 or to the sharp devaluations in East Asia in 1997-98, in Russia in August 1998, and in Brazil in January 1999, the collapse of unilateral exchange rate pegs often preceded acute financial and macroeconomic crises. Despite recent failures, however, exchange rate pegs remain a prevalent policy choice. Calvo and Reinhart (2000) argue that the exchange-rate volatility that accompanies a floating exchange rate regime is particularly onerous to emerging markets, and thus can be a worse policy choice than a peg that reduces the variability of the exchange rate, even if it does not attain the complete confidence of investors. Given the continued prevalence of pegs, it is worth seeking additional understanding of what makes a peg successful or not.

For this reason, we find it useful to study what was arguably the most successful unilateral exchange rate peg: Austria's peg to the Deutsche mark prior to Austria's entry into the European Monetary System in 1995. An estimated model of Austrian monetary policy mechanics helps identify salient features that made the Austrian peg credible to the public. We then apply the same model to monetary policy in Thailand: among the East Asian countries that eventually devalued, Thailand had maintained the tightest peg to the U.S. dollar prior to July 1997. The conventional wisdom is that the currency crisis in Thailand came without warning and caught financial markets by surprise. (Corsetti, Pesenti, and 
Roubini, 1999, Halcomb and Marshall, 2001.) We investigate whether there were any contrasts between the Austrian and Thai pegs that would have hinted at problems for Thailand prior to July 1997.

The next section discusses alternative exchange-rate regimes to put the unilateral peg in context. The third section presents an empirical model of monetary policy to describe the mechanics with which Austria pegged its exchange rate. The fourth section applies the same model to describe Thailand's monetary policy and the contrast with Austria.

\section{ALTERNATIVE EXCHANGE-RATE REGIMES}

As a prelude to an analysis of the mechanics of a unilateral exchange-rate peg, it is useful to describe the spectrum of alternative exchange rate regimes. In addition to unilateral exchange-rate pegs, there are five other exchange rate regimes: a floating rate, multilateral exchange rate pegs, currency boards, dollarization, and currency union. We describe here where the unilateral peg lies

along the spectrum. Since the end of the Bretton Woods system of fixed exchange rates in 1973, floating exchange rates have displayed a very high degree of variability without a corresponding increase in the variability of exchange-rate fundamentals (Flood and Rose, 1999). Moreover, Hausmann, Panniza, and Stein (1999) have shown that emerging markets in Latin America that have attempted to allow their exchange rates to float have experienced greater interest-rate volatility than fixed-rate regimes. For this reason, Calvo and Reinhart (2000) 
argue that floating exchange rates can have destabilizing effects on emerging markets.

For the next four regimes—all variants of fixed exchange rates—we start with the type of fixed rate that is closest to a float and move along the spectrum from there. In the first three regimes, a home country unilaterally fixes its currency to an "anchor" currency. The unilateral nature of the regime implies that the anchor country is not obligated to assist the home country if its currency comes under speculative attack. In a pegged regime, it is incumbent on the pegging country to set a monetary policy that always appears to currency traders to be consistent with the preannounced conversion rate. The best way to uphold this commitment is to run a monetary policy that is similar to that in the anchor country in terms of inflation rates and credit expansion. A pegging regime is more resistant to speculative attack if banks and other institutions hold an amount of foreign-exchange reserves that is at least as great as the quantity of short-term debt denominated in foreign currencies they have issued. Taiwan, for example, was largely immune to the Asian crisis of 1997-98 due to its large holdings of foreign exchange reserves. Many other emerging markets, however, intend to be net borrowers in foreign currencies and they attract foreign lending by establishing a peg and promising a stable exchange rate. The best way to keep this promise is to run a monetary policy that closely mimics that of the anchor country. 
A currency board differs from a unilateral peg in that the home country no longer sets its own monetary policy. Instead, the size of the monetary base is determined by monetary policy in the anchor country and capital flows. The currency board arrangement leaves no room for policies that are inconsistent with the fixed exchange rate because the only policy is a commitment to adjust the monetary base in tandem with flows of foreign exchange reserves in and out of the central bank. As a consequence, the home country's central bank can no longer act as a lender of last resort to the domestic banking sector; thus, speculative attacks can take place against banks instead of the currency.

Dollarization represents the unilateral decision to enact two formal changes. ${ }^{1}$ The first change is that all local currency in circulation plus vault cash in banks is redeemed for U.S. dollars at some announced conversion rate and is then destroyed. The second change involves transforming all contracts denominated in local currency into contracts in U.S. dollars at the conversion rate. Dollarization, which has recently taken place in Ecuador, has received increasing attention in academic and policy circles.

Exchange rates can also be fixed through multilateral arrangements, although these require more coordination and negotiation than unilateral pegs. Two multilateral systems are multilateral pegs and currency unions. In a multilateral peg, the distinction between the anchor currency and the pegging currency becomes blurred, because the participating countries are obligated to 
take monetary policy measures to defend the exchange rate peg. The prime example of a multilateral peg is the European Monetary System prior to the adoption of a single currency in January 1999. A currency union, in contrast, consists of an agreement to merge several currencies to fix the exchange rates and unify their monetary policymaking permanently. The European Monetary Union, undertaken in 1999, is the most prominent currency union.

\section{A MODEL OF MONETARY POLICY MECHANICS FOR A UNILATERAL PEG}

In practice, nearly all central banks implement monetary policy by setting a short-term interest rate as a policy instrument. A central bank trying to maintain an exchange rate peg will focus on the interest rate differential between the shortterm rate in its domestic currency and the prevailing short-term rate in the anchor currency. If the home currency comes under selling pressure, an increase in the interest rate differential can attract buyers by convincing them that higher domestic interest rates will keep domestic inflation in check, prevent a devaluation, and result in excess returns to the domestic currency relative to the anchor currency. In the long run, the pegging central bank must keep domestic inflation rates close to inflation in the anchor currency. By harmonizing the inflation rates, the central bank prevents the real exchange rate from appreciating to unsustainable levels at the pegged nominal exchange rate. Speculators often bet

\footnotetext{
${ }^{1}$ The term dollarization pertains to adopting the U.S. dollar; however, another major currency could be adopted as well.
} 
that central banks that have allowed substantial appreciation of the real exchange rate through relatively high domestic inflation will choose to break the peg and devalue, rather than let the domestic economy stagnate for a prolonged period with a high, uncompetitive real exchange rate.

We preface our presentation of a model of monetary policy mechanics by noting that monetary policy decisions do not strictly obey a particular formula or equation. Nevertheless, central banks do not have to implement in a literal fashion a model of monetary policy for the model to be useful. In fact, central banks often monitor such models themselves, because these models provide useful information about the rate of inflation that is likely to result from recent policy decisions.

In our empirical model of monetary policy mechanics, we assume that a pegging central bank adjusts the policy instrument, $i$ (the interest rate differential), according to a forecast of the relationship between the policy instrument and domestic price inflation, $\pi$ :

$$
\Delta i_{t}=\mathrm{E}_{t \mid t-1}\left[\Delta i_{t}+\pi_{t}\right]-\pi_{0 t}
$$

where $\pi_{0 t}$ is the desired inflation rate, which is presumably close to the rate of inflation expected in the anchor currency. Note that this use of a forecast to choose the policy instrument setting is analogous to setting a money-supply instrument, $m$ in logs, according to a velocity forecast:

$$
\Delta m_{t}=\Delta y_{0 t}-\mathrm{E}_{t \mid t-1}[\Delta y-\Delta m]
$$


where $y$ is nominal gross domestic product (GDP) in logs and $\Delta y_{0 t}$ is the desired rate of nominal GDP growth at time $t$. One difference is that, in the latter formulation, the forecasted quantity, $\Delta y-\Delta m$, is a well-known relation (velocity growth), whereas in the former, the forecasted quantity, $\Delta i+\pi$, is not. ${ }^{2}$ In either case, if policy is set according to the forecast and the forecast is correct on average, then the desired inflation or nominal GDP growth rate will be achieved on average. ${ }^{3}$

For a pegging central bank, we add to equation (1) two feedback terms that indicate the response to an exchange-rate gap and an inflation gap. The exchange-rate gap, $(e-\widetilde{e})$, is between the actual and target exchange rate. The inflation gap, $\left(\pi-\pi^{f}\right)$, is between inflation in the home country and the anchor country:

$$
\Delta i_{t}=\mathrm{E}_{t \mid t-1}\left[\Delta i_{t}+\pi_{t}\right]-\pi_{0 t}+\lambda_{1}\left(\pi-\pi^{f}\right)_{t-1}+\lambda_{2}(e-\widetilde{e})_{t-1}+\varepsilon_{t}
$$

Not all of these feedback terms will be significant for both Austria and Thailand, but we estimated identical models for both countries to highlight the differences between their policies and not different models of policy. An error term $\varepsilon$ is added to equation (3) to indicate that no central bank follows such an interest rate rule perfectly. In practice, we assume the error term has a student- $t$ distribution with $n$ degrees of freedom to allow for occasions of large deviations between the

\footnotetext{
${ }^{2}$ An equivalent set-up to equation (1) would be to forecast $\Delta i+\Delta \pi$ to target the change in inflation as $\pi_{0 t}-\pi_{t-1}$.

${ }^{3}$ Dueker and Fischer (1998) discuss the forecasting of the ratio between the nominal target variable and the policy instrument.
} 
actual and model-implied policy settings. The coefficients $\lambda_{1}$ and $\lambda_{2}$ indicate to what degree the respective gaps alter this period's desired rate of inflation from the baseline level of $\pi_{0}$.

The model of monetary policy must infer a target value of the exchange rate because central banks allow even strongly pegged exchange rates to drift a bit over long periods of time, and they do not announce precisely the extent to which the exchange rate target has incorporated this drift. In this model, the implicit target exchange rate that appears in the exchange rate gap in equation (3) is a weighted average of last period's target and last period's actual rate (in logs):

$$
\widetilde{e}_{t}=\delta \widetilde{e}_{t-1}+(1-\delta) e_{t-1}
$$

Gradual rebasing of the target occurs for values of $\delta$ less than one. Small shifts in the exchange rate are gradually accommodated into the target rate. As $\delta$ decreases from one, the rate of accommodation increases. Because $\delta$ is an estimated parameter, the model infers a path for the exchange-rate target that best explains the central bank's policy responses as measured by interest rate adjustments.

\section{Applying the Model to Austria's Peg}

In order to use this model as a device to describe monetary policy mechanics over a relatively long sample period, it is realistic to allow some of the parameters to vary across time. Therefore, we make several parameters subject to two-state Markov switching, which is a parsimonious way to introduce variation into the parameter values. For example, even if Austria were to harmonize its 
intended inflation rate with Germany's, we would not expect Austria's baseline inflation, $\pi_{0}$, to be constant over the entire sample period. The German Bundesbank's informal inflation target varied between 4.5 and 2 percent (or less) between 1975 and 1994, according to von Hagen (1995). Thus, we can expect that estimates of $\pi_{0}$ for Austria will switch between two values that lie roughly in this range. Other parameters are not expected to remain absolutely constant across the entire sample either. For example, the exchange-rate target will sometimes be nearly constant, $(\delta=1)$, whereas at other times it will adjust to accommodate changes in the prevailing exchange rate, $(\delta<1)$. Markov switching is a method that lets economists use the data and model to infer when parameter shifts occurred, rather than impose their own judgment. Also subject to switching are the feedback parameters, $\lambda_{1}$ and $\lambda_{2}$, and the variance $\sigma^{2}$. We use three different binary Markov state variables, $S 1, S 2$, and $S 3$, with transition probabilities, $\left(p_{i,} q_{i}\right), i=1,2,3$, where $p_{i}=\operatorname{Prob}\left(S i_{t}=0 \mid S i_{t-1}=0\right)$ and $q_{i}=\operatorname{Prob}\left(S i_{t}=1 \mid S i_{t-1}=1\right){ }^{4}$ The first state variable governs switching in $\pi_{0}$. The second governs switching in the feedback parameters $\lambda_{1}, \lambda_{2}$, and $\delta$. The third governs switching in $\sigma^{2}$, the variance of the error term. A more parsimonious model would tie all of these parameters to a single state variable, but it seems too restrictive to force the inflation target to move in tandem with the rebasing of the exchange-rate target.

\footnotetext{
${ }^{4}$ Technical details regarding the estimation procedure are in the Appendix and Dueker and Fischer
} 
The data used to estimate the model are short-term interest rates and inflation rates for Austria and Germany, as well as the exchange rate between the Austrian schilling and the Deutsche mark. As the most representative short-term interest rates, we use the three-month repurchase rates for Austria and Germany. The consumer price index (CPI) is the inflation measure. Our sample consists of quarterly data from 1972 to the end of 1994. On January 1, 1995, Austria officially entered the Exchange Rate Mechanism of the European Monetary System, whereupon the exchange rate became part of a multilateral peg. ${ }^{5}$

Discussion of the construction of the forecasts, $\mathrm{E}_{t \mid t-1}\left[\Delta i_{t}+\pi_{t}\right]$, and the likelihood function is included in the appendix.

Parameter estimates for Austria from 1972:Q2 through 1994:Q3 are in Table 1, where subscripts $a$ and $b$ denote the pair of values of parameters subject to Markov switching. The $a$ values correspond with the $p$ transition probabilities, and the $b$ values correspond with the $q$ transition probabilities. Parameter values reported as equal to either zero or one converged arbitrarily close to those values and were not restricted in the estimation.

The estimates of Austria's baseline inflation rates, $\pi_{0 a, b}=(1.74,3.49)$, from Table 1 are quite close to the range of Germany's informal inflation targets

(1996).

${ }^{5}$ From 1974 to 1995, the Austrian National Bank unilaterally pegged the Austrian schilling to the Deutsche mark. This policy was known as the "Hard-Currency Policy." Hochreiter and Winckler (1995) discuss this policy regime in detail. 
of 2 to 4.5 or less. $^{6}$ The unconditional value of Austria's $\pi_{0}$ is 2.89 . We call $\pi_{0}$ a baseline inflation rate because it would be the inflation target if both the exchange-rate gap and the inflation gap were zero. To assess further whether Austrian monetary policy was aiming at a common rate of inflation with Germany, we estimated equation (3) for Germany, with the feedback coefficients $\lambda_{1}$ and $\lambda_{2}$ set to zero. The estimates of $\pi_{0 a, b}$ for Germany are $(0.71,3.50)$, with an unconditional value of 2.86, which is extremely close to Austria's 2.89. Thus, Austria's monetary policymakers revealed through their interest rate instrument settings a preference for the same inflation rate as that of Germany, even in the absence of feedback from the exchange rate and inflation gaps.

Figure 1 shows a plot of the probability-weighted values of $\pi_{0}$ for Austria and Germany and shows a high degree of correspondence between the two. Austria's period-by-period inflation target, conditional on the inflation and exchange rate gaps, equals $\pi_{0 t}-\lambda_{1 t}\left(\pi-\pi^{f}\right)_{t-1}-\lambda_{2 t}(e-\widetilde{e})_{t-1}$.

Since $\lambda_{1}$ equals zero in both states, Austria's monetary policy took feedback from the exchange rate only. One conclusion we can draw is that strong feedback from the inflation gap is not necessary for a peg to succeed, provided that the pegging country has chosen the same baseline inflation rates, $\pi_{0}$, as the anchor country.

Figure 2 shows Austria's period-by-period inflation target plotted against the actual rate of inflation in Germany calculated as the change in the CPI in the four most recent quarters. This chart suggests that Austria imported inflation from

\footnotetext{
${ }^{6}$ These results are presented in detail in Dueker and Fischer (2000).
} 
Germany during the two peaks in German inflation, the first in 1975 and the second in 1982. German inflation influenced Austrian monetary policy through the exchange rate because $e-\widetilde{e}$ tended to be negative when German inflation was high. Figure 3 presents the model-implied exchange-rate target, $\widetilde{e}$, and the actual exchange rate. ${ }^{7}$ In studying Figure 3, one must keep the scale in mind, because the schilling fluctuated in a relatively narrow band throughout these 20 years. For most of the period, the exchange-rate gap was negligible; therefore, Austrian monetary policy focused on keeping its inflation rate close to $\pi_{0}$, which Austrian policymakers had chosen to be close to Germany's inflation target. Nevertheless, the magnitude and significance of the feedback coefficients on exchange-rate gaps, $\left(\lambda_{2}\right)$ in Table 1 , indicate that Austrian monetary policy remained poised to act decisively to close any exchange-rate gap that developed.

\section{The Model of Peg Mechanics Applied to Thailand}

Among the East Asian countries that were forced to break an exchangerate peg between 1997 and 1998, Thailand was the first, and perhaps the most surprising, to devalue. Prior to 1997, Thailand had maintained one of the tightest and most longstanding pegs in Asia. To understand the mechanics behind Thailand's peg of the Thai baht to the U.S. dollar, we estimate equation (3) for Thailand and compare the results with Austria. As with Austria, we used the

\footnotetext{
${ }^{7}$ In the graph the rates appear in levels, but they enter equation (3) in logarithms times 100.
} 
three-month interest rate and the CPI along with the exchange rate. For Thailand, however, we used monthly data from January 1990 through June 1997, one month before the peg was broken.

Table 2 reports the parameter estimate: these show that Thailand's baseline inflation rate, $\pi_{0 t}$, had an unconditional probability-weighted value of 6.5, which is well above the average level of U.S. inflation for that period, 3.1 percent. Hence the only way that Thailand's period-by-period inflation target could remain close to the U.S. rate would be through feedback from the inflation and exchange-rate gaps. In contrast, Austria's baseline inflation rate closely matched the corresponding rate in Germany. Figure 4 shows that Thailand's inflation rate consistently exceeded the inflation rate in the United States, but by less than 3.4 percent (6.5 minus 3.1), because of feedback from the inflation gap. Parameters $p_{2}$ and $q_{2}$ are the transition probabilities for switching in the feedback coefficients, $\lambda_{1}$ and $\lambda_{2}$, and both show very little persistence. In fact, since $p_{2}+q_{2}<1$, the feedback coefficients show negative serial correlation, which implies oscillatory behavior in the period-by-period inflation target,

$$
\pi_{0 t}-\lambda_{1 t}\left(\pi-\pi^{U S}\right)_{t-1}-\lambda_{2 t}(e-\widetilde{e})_{t-1} .
$$

For Thailand, the feedback coefficients $\lambda_{1 b}$ and $\lambda_{2 b}$ imply strong responses to inflation and exchange-rate gaps. For Austria, the feedback coefficients display no serial correlation — either positive or negative — because $p_{2}+q_{2}$ is essentially equal to one; moreover, feedback from the gaps does not play an important role in determining Austria's interest rate. 
Figure 5 shows that—after 1995 especially—Thailand's period-by-period inflation target, which is conditional on feedback from the gaps, appears to inherit negative serial correlation from switching in the feedback coefficients. Figure 6 plots the posterior probability of the high-feedback state and confirms that the fluctuation in the probability from month to month went from a relatively narrow range, between 30 percent and 60 percent prior to mid-1995, to a much greater range thereafter. ${ }^{8}$ The discussion that follows centers on why Thailand's policy feedback coefficients became more volatile starting in mid-1995.

The exchange value of the U.S. dollar - to which the baht was pegged-reached a record low in May 1995 against the Japanese yen, at which time the dollar was also weak against other major currencies. Prior to May 1995, the dollar had depreciated consistently against the yen since early 1990 (as shown in Figure 7). Since Japan is both a major trading partner and a rival exporter with Thailand, the baht-dollar peg was able to sustain a rising real exchange rate with the dollar during the period that the yen was appreciating against the dollar. ${ }^{9}$ In May 1995, however, the dollar-yen exchange rate peaked and the real exchange value of the yen began to depreciate against the dollar. To remain competitive in international markets, Thailand felt compelled at this juncture to prevent further appreciation of the real exchange value of the baht relative to the dollar. Clearly,

\footnotetext{
${ }^{8}$ The posterior probability is the probability of a state at time $t$ conditional on the data up to and including time $t$.

${ }^{9}$ The real exchange rate rises for Thailand if the inflation rate is greater in Thailand than in the United States and the nominal exchange rate (expressed in baht per dollar) does not increase by an equal magnitude.
} 
it would have been difficult for Thailand if the real exchange value of the baht had been expected to continue to increase relative to the dollar at a time when the real exchange value of the dollar was rising relative to the world's other major currencies.

One key aspect of the credibility of an exchange-rate peg is whether the market believes that the pegging country's economy remains competitive internationally, given any appreciation of its real exchange rate that has taken place during the peg. Thailand's appreciating real exchange value relative to the dollar may have appeared sustainable during a period when many of the world's other major currencies were appreciating relative to the dollar, but not when this course reversed. For this reason, it is not surprising that Figure 5 shows that Thailand's period-by-period inflation target was kept centered on a mean closer to the U.S. inflation rate after mid-1995. An obvious question, however, is why the inflation target was so volatile around this lower mean? The answer probably lies in the extreme inflows of foreign capital that Thailand was receiving at the time. On one hand, raising the short-term interest rate helped to reduce domestic demand and inflation. On the other hand, high interest rates helped spur additional flows of foreign capital to Thailand in search of high returns. In fact, the amount of foreign capital that flowed to Thailand in 1996 was massive, at a level equal to 13 percent of GDP (Grenville, 2000, p. 6). The tension between wanting to control domestic demand and inflation in the short run and worrying about the consequences of the huge capital inflows could explain the apparent stop-go 
behavior of Thailand's monetary policy after mid-1995. Such a balancing act - the rapid fluctuation of the feedback coefficients after 1995, shown in Figure 6-was not a sustainable policy for the long run. By July 1997, speculators had broken the exchange rate peg. Halcomb and Marshall (2001) review evidence that Thailand's devaluation of the baht in July 1997 was not widely anticipated in financial markets. They observe that the timing of a currency crisis can be difficult to predict, even if one knows that a peg is not on solid footing for the long run.

In the face of such massive capital inflows, it seems apparent in hindsight that Thailand probably should not have maintained such a hard peg. Instead, the monetary policy authority could have signaled by mid-1995 a greater degree of flexibility with respect to adjusting the peg. Indeed, the Bank of Thailand now practices inflation targeting with a floating exchange rate (Sonakul, 2000, p. 2). Figure 8 shows the baht-dollar exchange rate along with the model-implied target rate, $\widetilde{e}$. This chart suggests that the Bank of Thailand allowed the baht to depreciate by about four percent in the 18 months prior to July 1997 . Clearly this rate of depreciation was not enough to counteract the large interest rate differential shown in Figure 9. The size of the interest rate differential between Thailand and the United States in the early part of 1995 suggested that the Bank of Thailand might have signaled a willingness to let the baht depreciate at a rate of about five percent per year. Such a rate of expected depreciation also might have helped alleviate the capital inflows by discouraging domestic borrowers 
from taking dollar-denominated loans. Instead, the Bank of Thailand chose to defend the peg by squeezing speculators who tried to take short positions in baht by imposing high interest rates and pressure on domestic banks not to lend to offshore currency traders (Halcomb and Marshall, 2001).

\section{SUMMARY AND CONCLUSIONS}

Our empirical results for Austria's successful exchange-rate peg highlight the importance the Austrian National Bank placed on consistently maintaining Austria's inflation rate close to that of Germany. In so doing, Austria prevented the real exchange value of the schilling vis-a-vis the Deutsche mark from drifting far from its initial value. Furthermore, the Austrian economy had enough in common with the German economy that the Austrian National Bank was willing to let the real exchange value of the schilling experience the vicissitudes in the real exchange value of the Deutsche mark against other major currencies. One lesson for pegging countries is that they ought to behave like assiduous inflation targeters even when there is no pressure on the exchange rate. The key is that the inflation target should be the same inflation target used in the anchor country because the nominal exchange can no longer move to correct an overvalued real exchange rate. Feedback from the inflation and exchange-rate gaps did not appear to play an important role in Austria's successful peg, given that Austria followed Germany's inflation target closely even before gaps developed. A second lesson is to take care in choosing an anchor currency because the major 
currencies experience wide swings against one another. It makes no sense to tie one's currency to the dollar if the fluctuations in the exchange value of the dollar against other major currencies are difficult to withstand.

Both of these lessons appear to apply to Thailand's peg to the U.S. dollar. The Bank of Thailand allowed the domestic inflation rate to exceed the U.S. inflation rate prior to mid-1995, based on the depreciation of the U.S. dollar against other major currencies, principally the Japanese yen. In fact, the estimates of Thailand's baseline inflation rate were more than twice the average U.S. inflation rate. If the Bank of Thailand truly had a long-term commitment to pegging its currency to the dollar, it would not have tried to take advantage of the depreciation in the dollar against the yen by inflating. This policy led to trouble when the U.S. dollar began to appreciate against the yen in the second half of 1995. At this point, Thailand's policy response to the inflation gap between Thailand and the United States was strong, but it was not implemented consistently. The model estimates reveal unstable, oscillatory behavior in the feedback from the inflation gap, probably due to the tension between the desire for high interest rates to control inflation and concern for the size of the capital inflows that high interest rates were attracting. In these circumstances, it would have been exceedingly difficult for inflation in Thailand to undershoot the U.S. inflation rate by a significant margin. The Bank of Thailand might have fared better by announcing gradual depreciation of the nominal exchange rate, starting in mid-1995, before speculators began to apply their own pressure. Since the 
crisis in 1997-98, the Bank of Thailand has announced a new inflation-targeting regime in place of an exchange-rate peg. The Bank of Thailand believes that the new regime will be less prone to boom and bust cycles than was the peg to the dollar (Sonakul, 2000). Thus, Thailand is one emerging market that has decided that it can find greater stability by promising low inflation than by promising a particular exchange rate. Time will tell whether the disadvantages of floating exchange rates to emerging markets will weigh as heavily as Calvo and Reinhart (2000) suggest. What is clear from the results presented here is that Thailand's exchange rate peg prior to July 1997 never had the strong underpinnings that sustained Austria's peg to the Deutsche mark. 


\begin{tabular}{|c|c|c|}
\hline \multicolumn{3}{|c|}{ Table 1 Parameter Estimates for Austria } \\
\hline$\pi_{0 a, b}$ & $\begin{array}{c}1.740 \\
(0.612)\end{array}$ & $\begin{array}{c}3.494 \\
(0.304)\end{array}$ \\
\hline$\lambda_{1 a, b}$ & 0 & 0 \\
\hline$p_{1}, q_{1}$ & $\begin{array}{c}0.887 \\
(0.087)\end{array}$ & $\begin{array}{c}0.941 \\
(0.048)\end{array}$ \\
\hline$\lambda_{2 a, b}$ & $\begin{array}{c}1.124 \\
(0.105) \\
\end{array}$ & $\begin{array}{c}0.338 \\
(0.091) \\
\end{array}$ \\
\hline$\delta_{a, b}$ & 1 & $\begin{array}{c}.823 \\
(0.084)\end{array}$ \\
\hline$p_{2}, q_{2}$ & $\begin{array}{c}0.231 \\
(0.269)\end{array}$ & $\begin{array}{c}0.743 \\
(0.174)\end{array}$ \\
\hline$\overline{\sigma_{a, b}^{2}}$ & $\begin{array}{c}0.057 \\
(0.028)\end{array}$ & $\begin{array}{c}2.121 \\
(1.074)\end{array}$ \\
\hline$p_{3}, q_{3}$ & $\begin{array}{c}.948 \\
(0.041)\end{array}$ & $\begin{array}{c}0.931 \\
(0.578)\end{array}$ \\
\hline$\overline{1 / 1 / n}$ & $\begin{array}{c}0.199 \\
(0.161)\end{array}$ & \\
\hline Log-likelihood & -115.9 & \\
\hline \multicolumn{3}{|c|}{$\begin{array}{c}\text { Note: } \text { standard errors are in parentheses; } \\
p_{1}, q_{1} \text { are transition probabilities for switching in } \pi_{0} ; \\
p_{2}, q_{2} \text { are transition probabilities for switching in } \\
\lambda_{1}, \lambda_{2}, \delta ; \\
p_{3}, q_{3} \text { are transition probabilities for switching in } \sigma^{2} .\end{array}$} \\
\hline
\end{tabular}




\begin{tabular}{|c|c|c|}
\hline \multicolumn{3}{|c|}{$\begin{array}{c}\text { Table } 2 \text { Parameter Estimates for Thailand } \\
\text { Monthly Data 1990:01 to 1997:06 }\end{array}$} \\
\hline$\overline{\pi_{0 a, b}}$ & $\begin{array}{l}3.863 \\
(2.102\end{array}$ & $\begin{array}{l}15.426 \\
(3.882)\end{array}$ \\
\hline$p_{1}, q_{1}$ & $\begin{array}{c}0.851 \\
(0.139)\end{array}$ & $\begin{array}{c}0.501 \\
(0.018)\end{array}$ \\
\hline$\overline{\bar{\lambda}} \overline{1 a, b}$ & 0 & $\begin{array}{c}1.415 \\
(1.422)\end{array}$ \\
\hline$\lambda_{2 a, b}$ & 0 & $\begin{array}{c}1.022 \\
(0.532)\end{array}$ \\
\hline$\delta_{a, b}$ & $\begin{array}{c}0.514 \\
(0.074)\end{array}$ & 1 \\
\hline$p_{2}, q_{2}$ & $\begin{array}{c}0.253 \\
(0.368)\end{array}$ & $\begin{array}{c}0.429 \\
(0.264)\end{array}$ \\
\hline$\overline{\sigma_{a, b}^{2}}$ & $\begin{array}{l}2.917 \\
(26.8)\end{array}$ & $\begin{array}{c}2.993 \\
(0.889)\end{array}$ \\
\hline$p_{3}, q_{3}$ & $\begin{array}{c}0.207 \\
(1.216)\end{array}$ & $\begin{array}{c}0.998 \\
(0.163)\end{array}$ \\
\hline $1 / n$ & 0 & \\
\hline Log-likelihood & -197.1 & \\
\hline \multicolumn{3}{|c|}{$\begin{array}{c}\text { Note: standard errors are in parentheses; } \\
p_{1}, q_{1} \text { are transition probabilities for switching in } \pi_{0} ; \\
p_{2}, q_{2} \text { are transition probabilities for switching in } \\
\lambda_{1}, \lambda_{2}, \delta ; \\
p_{3}, q_{3} \text { are transition probabilities for switching in } \sigma^{2}\end{array}$} \\
\hline
\end{tabular}




\section{Appendix}

The forecasts for equation (3) are taken from a model that allows for two types of uncertainty. The first arises from heteroscedasticity in the error terms. This is modeled by a Markov switching process, which tries to match the persistence of periods of high and low volatility in the data. The second source of uncertainty arises as economic agents are obliged to infer unknown or changing regression coefficients.

The model generating the forecasts is

$$
\begin{gathered}
\left(\Delta i_{t}+\pi_{t}\right)=\beta_{0 t}+\beta_{1 t} \Delta i_{t-1}+\beta_{2 t} \pi_{t-1}+\beta_{3 t} \Delta e_{t-1}+u_{t}, \\
\qquad u_{t} \sim \operatorname{Nominal}\left(0, h_{t}\right) \\
h_{t}=v_{0}^{2}+\left(v_{1}^{2}-v_{0}^{2}\right) R_{t} \\
\text { where } R_{t} \text { is } 0 \text { or } 1 \\
\text { Probability }\left(R_{t}=0 \mid R_{t-1}=0\right)=r_{1} \\
\operatorname{Probability}\left(R_{t}=1 \mid R_{t-1}=1\right)=r_{2}
\end{gathered}
$$

Variable $i$ is the interest rate differential, $\pi$ is consumer price inflation, and $e$ is the exchange rate in logs.

The time-varying coefficients assume that the state variables, $\beta_{t}$, follow a random walk process:

$$
\begin{aligned}
\beta_{t}= & \beta_{t-1}+v_{t} \\
& v_{t} \sim \operatorname{Normal}(O, Q) .
\end{aligned}
$$


The random walk assumption suggests that agents need new information before changing their views about the relationships among the variables. Moreover, the time-varying structure of the forecasts allows it to adapt to structural breaks in the relationships between the dependent and explanatory variables.

The maximum-likelihood estimates reported in Tables 1 and 2 are the result of estimating the following density function, which includes three Markov state variables denoted $S 1, S 2$ and $S 3$, where $Y_{t-1}$ is all information available through time $t-1$ :

$$
\sum_{t=1}^{T} \ln \left(\sum_{i=0}^{1} \sum_{j=0}^{1} \sum_{k=0}^{1} \operatorname{Prob} .\left(S 1_{t}=i, S 2_{t}=j, S 3_{t}=k \mid Y_{t-1}\right) L_{t}^{(i, j, k)}\right)
$$

The student- $t$ densities are

$$
\begin{aligned}
\ln L_{t}^{(i, j, k)}= & \ln \Gamma(.5(n+1))-\ln \Gamma(.5 n)-.5 \ln \left(\pi n \sigma_{S 3_{t}=k}^{2}\right) \\
& -.5(n+1) \ln \left(1+\frac{\varepsilon_{S 1_{t}=i, S 2_{t}=j,}^{2}}{n \sigma_{S 3_{t}=k}^{2}}\right),
\end{aligned}
$$

and $\Gamma$ is the gamma function. 


\section{REFERENCES}

Calvo, Guillermo A. and Reinhart, Carmen M. "Fixing for Your Life.” National Bureau of Economic Research Working Paper No. 8606, November 2000.

Corsetti, Giancarlo; Pesenti, Paolo and Roubini, Nouriel. "What Caused the Asian Currency and Financial Crisis?" Japan and the World Economy, October 1999, 11(3), pp. 305-73.

Dueker, Michael J. and Fischer, Andreas M. "Austria's Hard-Currency Policy: The Mechanics of a Successful Exchange Rate Peg." Center for Economic Policy Research Working Paper No. 2479, June 2000.

Dueker, Michael J. and Fischer, Andreas M. "A Guide to Nominal Feedback Rules and Their Use for Monetary Policy." Federal Reserve Bank of St. Louis Review, July/August 1998, 80(4), pp. 55-63.

Dueker, Michael J. and Fischer, Andreas M. "Inflation Targeting in a Small Open Economy: Empirical Results for Switzerland.” Journal of Monetary Economics, February 1996, 37(1), pp. 89-103.

Flood, Robert P. and Rose, Andrew K. "Understanding Exchange Rate Volatility without the Contrivance of Macroeconomics." Economic Journal, November 1999, 109(459), pp. F660-72.

Grenville, Stephen. "Exchange Rate Regimes for Emerging Markets." Bank for International Settlements Review, 3 November 2000, 97, pp. 5-14.

Halcomb, Darrin and David Marshall. "A Retrospective on the Asian Crisis of 1997: Was it Foreseen?” Chicago Fed Letter, January 2001.

Hausmann, Ricardo; Panizza, Ugo and Stein, Ernesto. "Why Do Countries Float the Way They Float?" Inter-American Development Bank Working Paper No. 418, May 1999.

Hochreiter, E. and Winckler, G. "The Advantage of Tying Austria's Hands: The Success of the Hard Currency Strategy." European Journal of Political Economy, 1995, 11(1), pp. 83-111.

Sonakul, M.R. Chantu Mongol. "Inflation Targeting -A New Monetary Policy Approach for Thailand." Bank for Internatinal Settlements Review, 27 November 2000, 106, pp. 1-2. 
von Hagen, Juergen. "Inflation and Monetary Targeting in Germany," in Leonardo Leiderman and Lars E.O. Svensson, eds., Inflation Targets. London: Center for Economic Policy Research Press, 1995, pp. 107-21., 1995. 
Figure 1. Inflation Targets

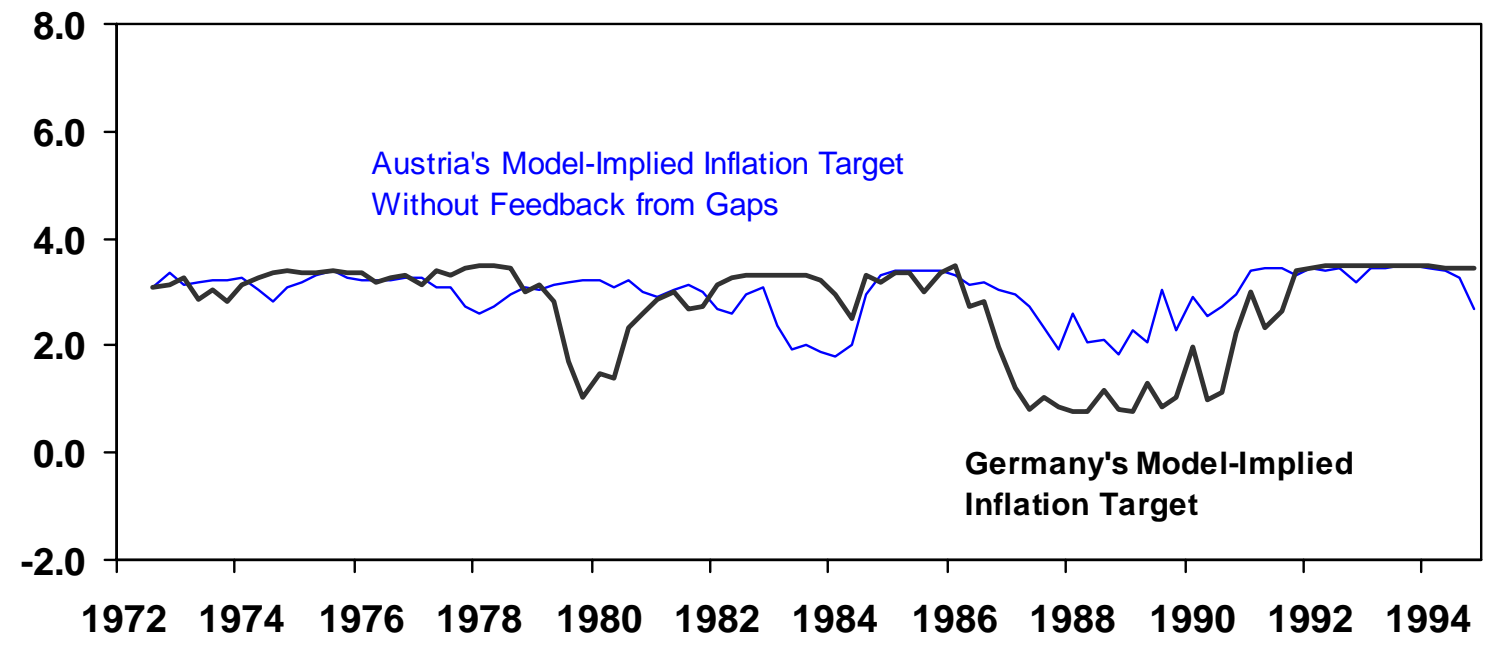

Figure 2. Austria's Feedback Rule

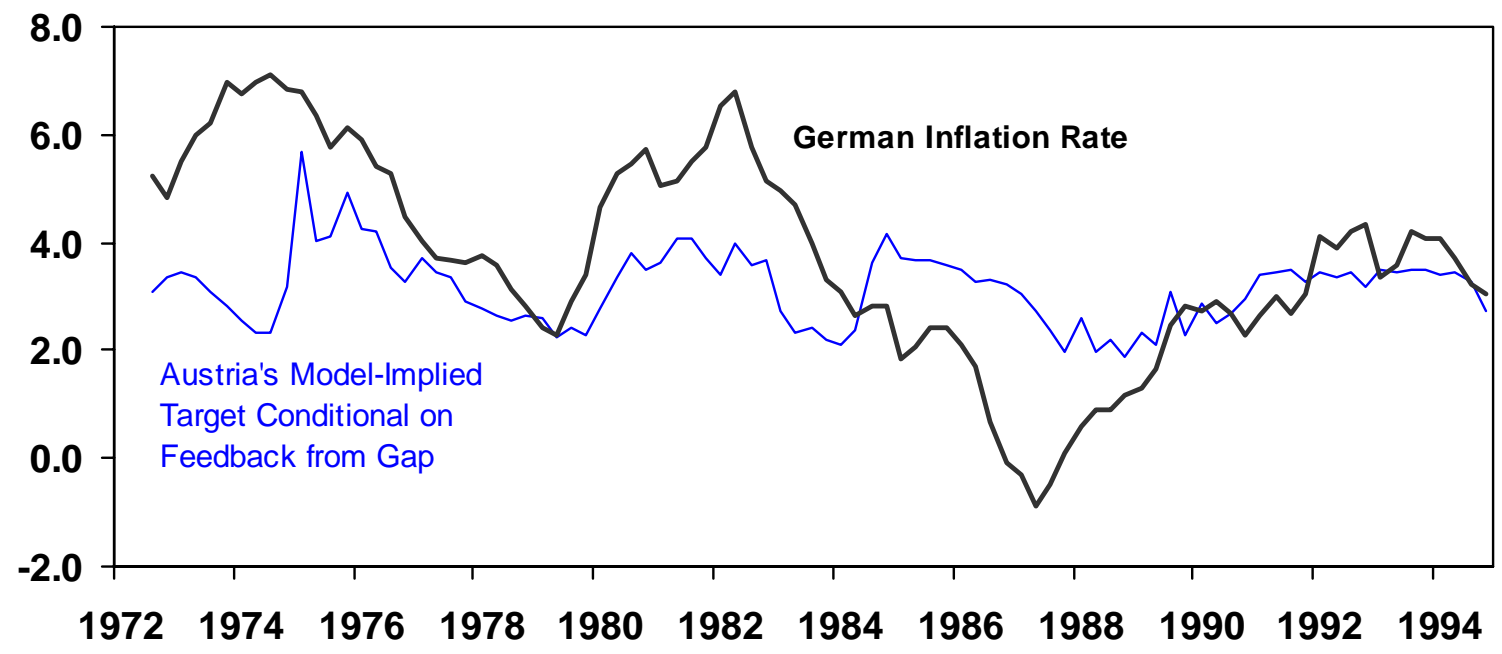


Figure 3. Schillings/Mark Exchange Rate

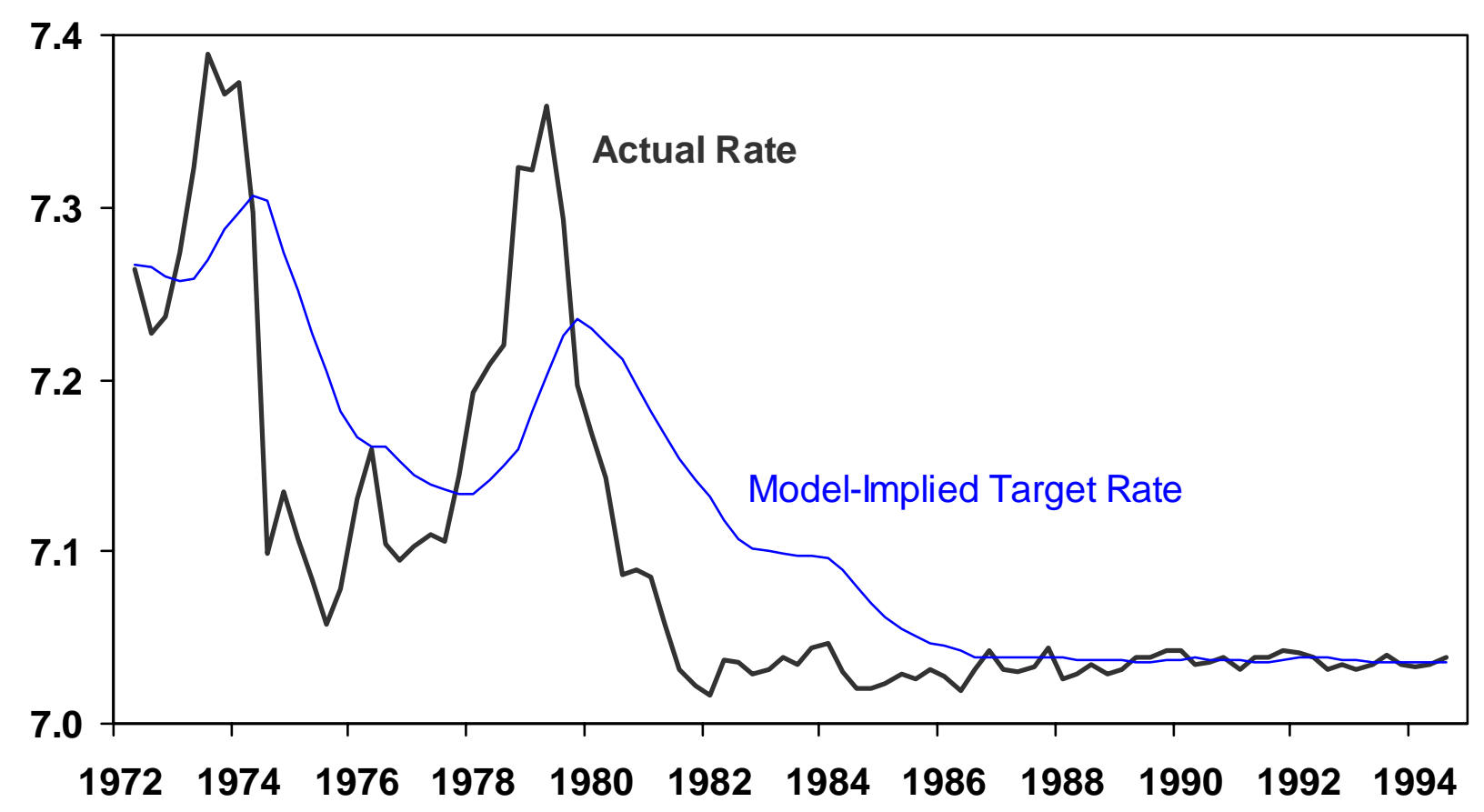


Figure 4. Year-Over-Year Inflation Rates of Thailand and the U.S.

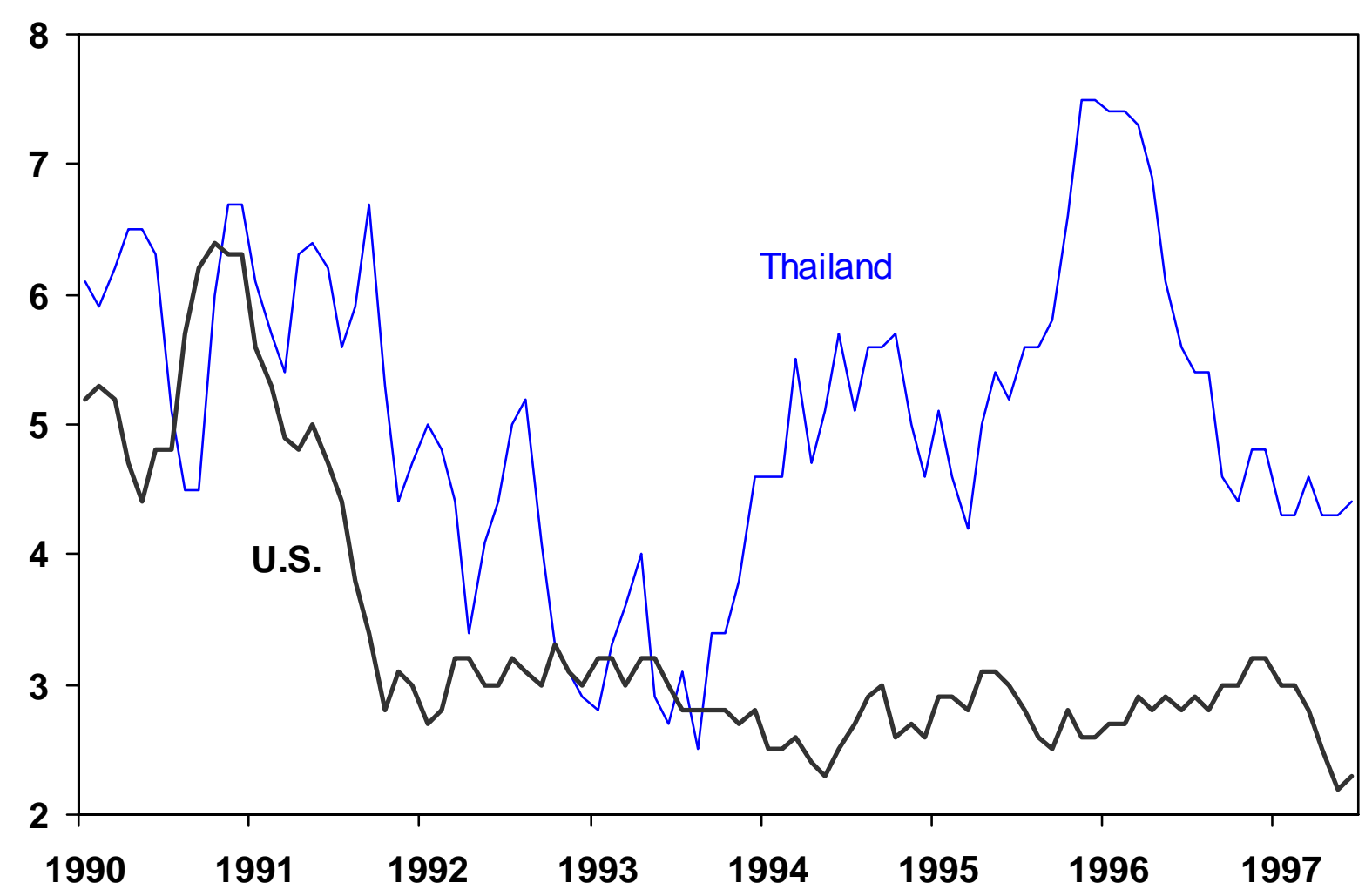


Figure 5. Thailand's Feedback Rule

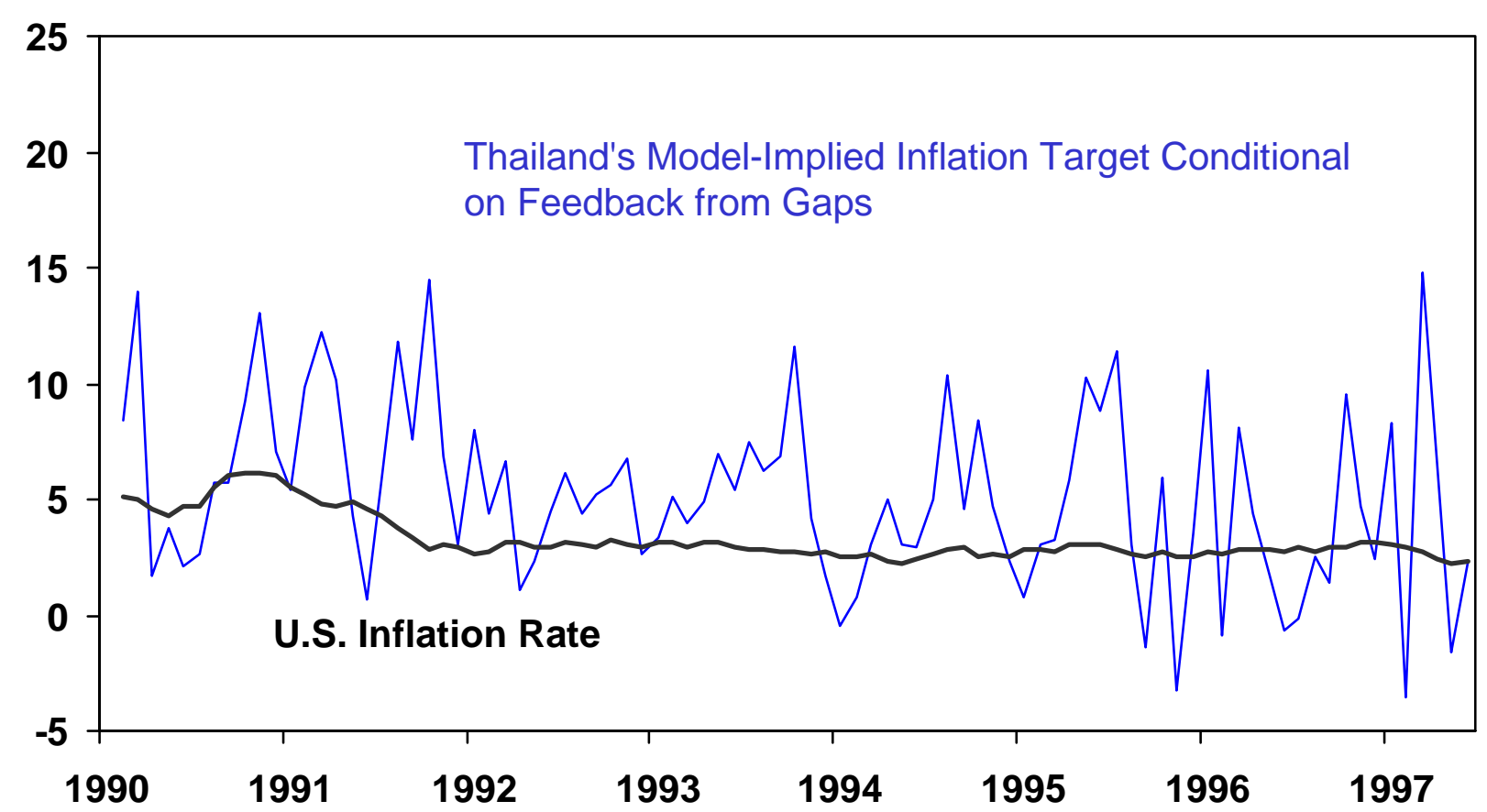


Figure 6. Thailand: Posterior Probability of the High-Feedback Coefficients on the Gaps

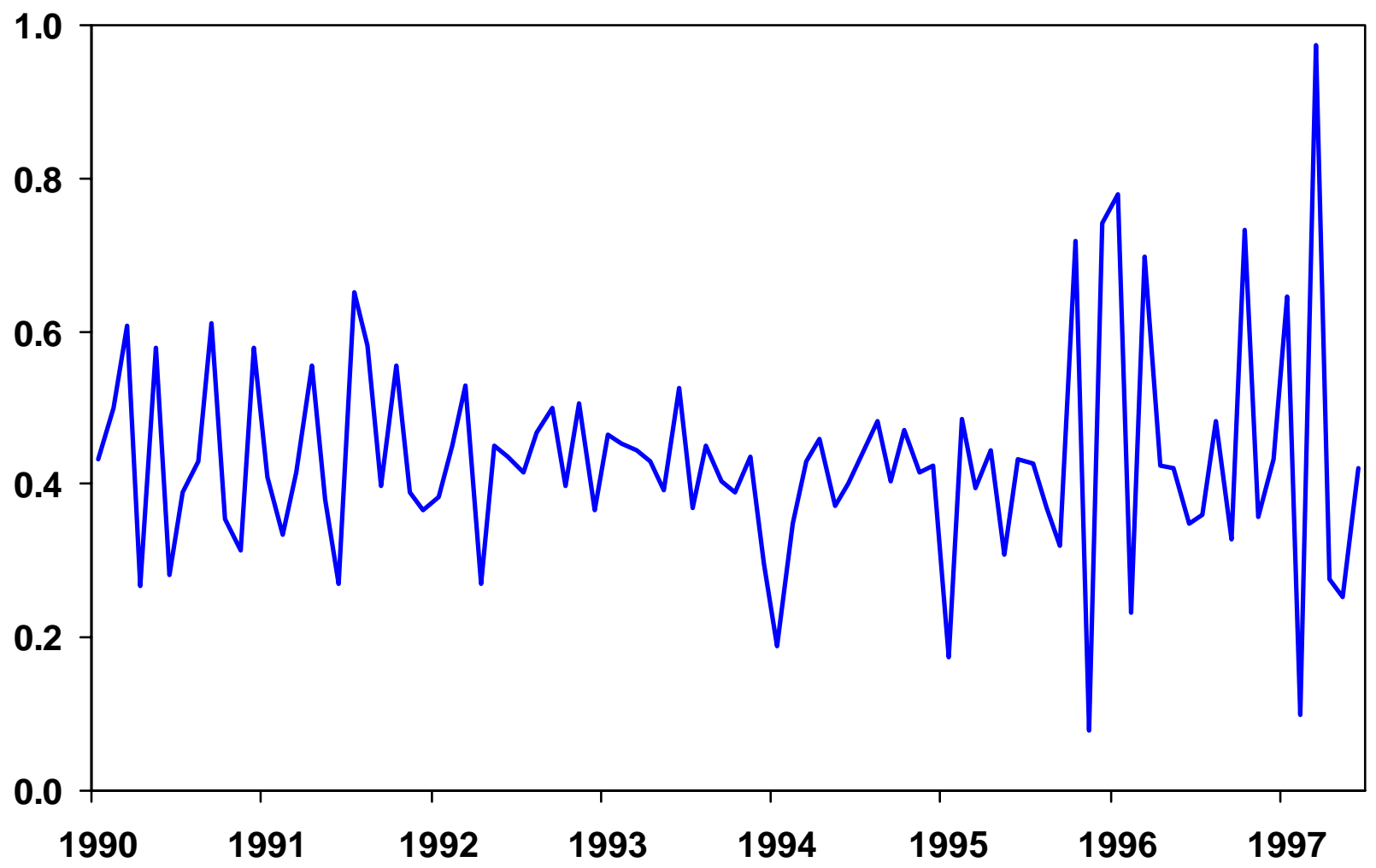


Figure 7. Yen/U.S. Dollar Exchange Rate

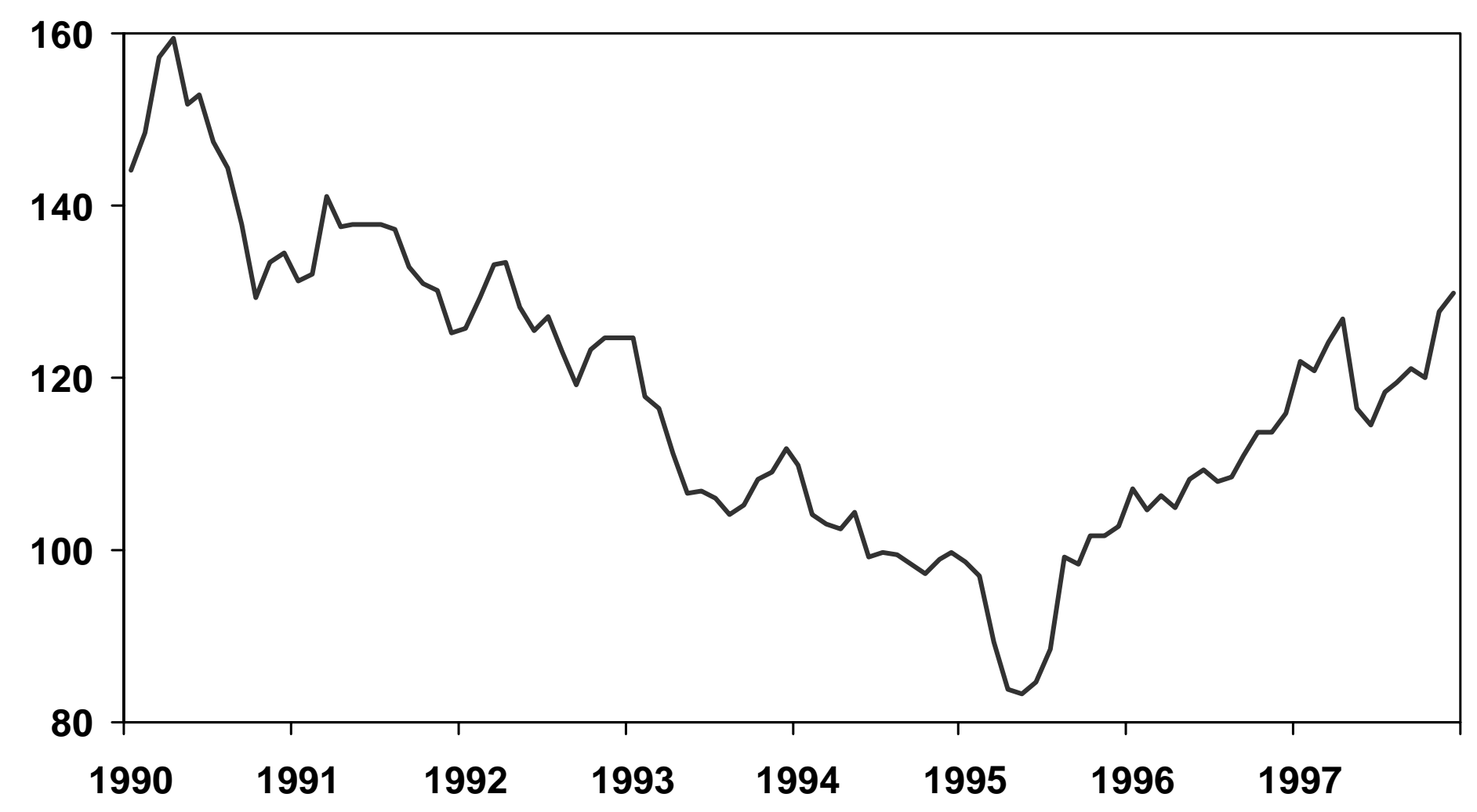


Figure 8. Baht/U.S. Dollar Exchange Rate

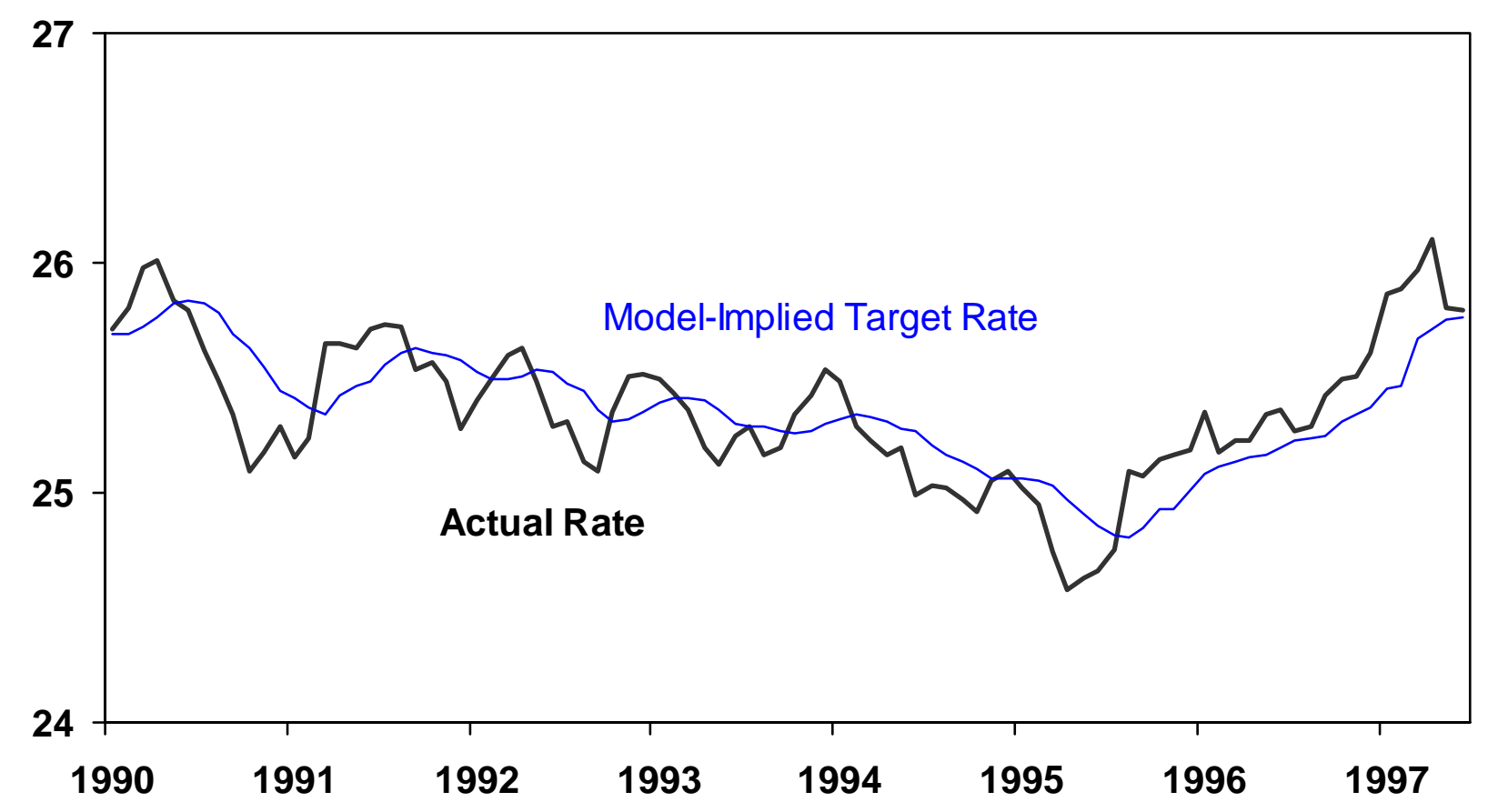


Figure 9. Short-Term Interest Rates in Thailand and U.S.

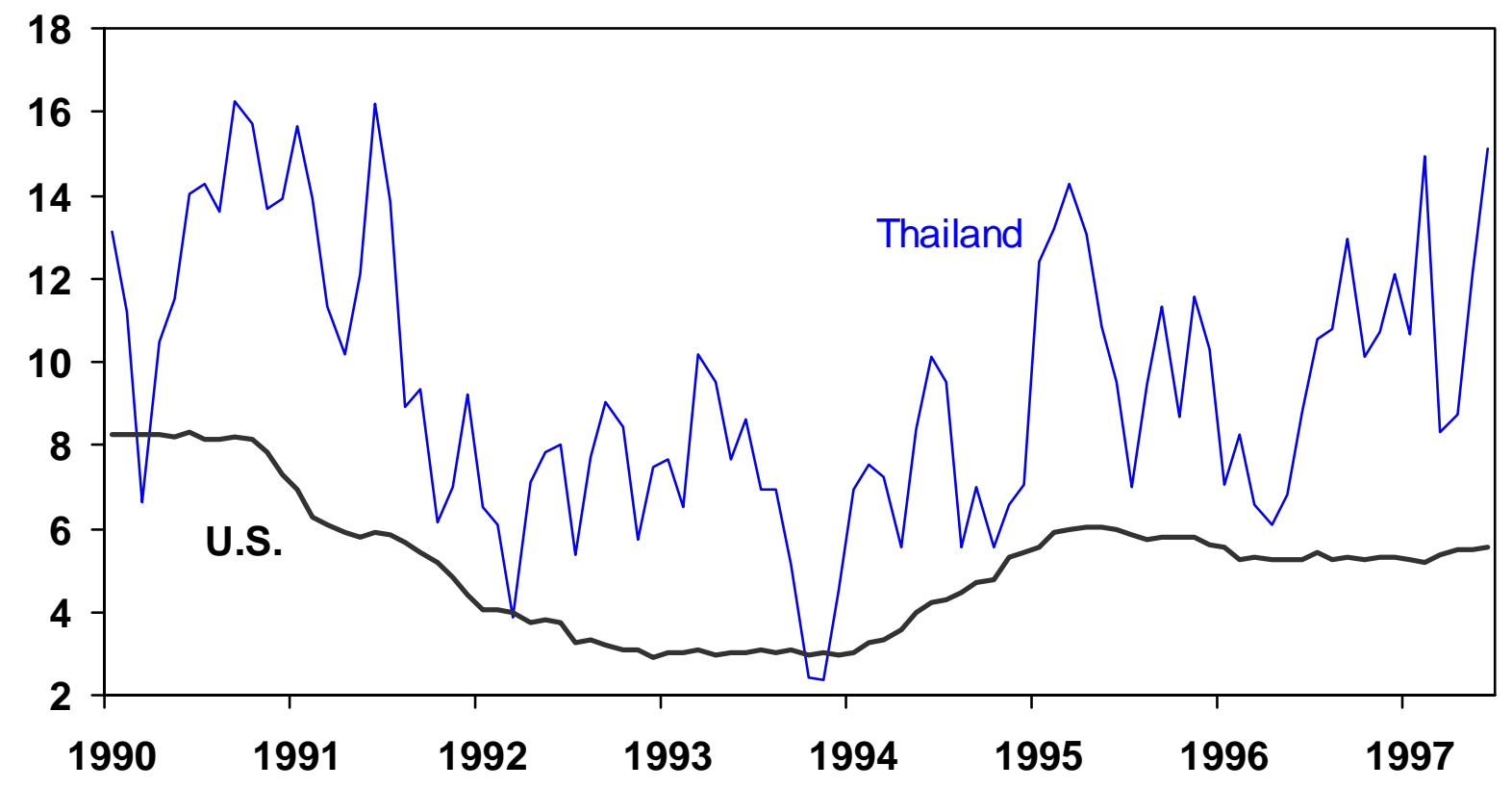

